\title{
PENGEMBANGAN MULTIMEDIA INTERAKTIF BERBASIS GAME 2D FLASH PADA PEMBELAJARAN MATEMATIKA MATERI PECAHAN SEDERHANA UNTUK SISWA KELAS III UPTD SDN BANYUAJUH 4 KAMAL
}

\author{
${ }^{1}$ Imani Puspita Sari, ${ }^{2}$ Mohammad Edy Nurtamam, ${ }^{3}$ Umi Hanik \\ 1,2,3 Prodi Pendidikan Guru Sekolah Dasar Fakultas Ilmu Pendidikan \\ Universitas Trunojoyo Madura
}

\begin{abstract}
The purpose of this development is to develop learning media in the form of $2 D$ Flash Interactive Multimedia based on learning mathematics in simple fractions which are valid, effective and interesting for class III of UPTD Banyuajuh 4 Elementary School in Kamal. This study uses the development model of Borg and Gall modified by Sugioyono. Based on the research conducted, the results of the validity of $2 D$ Flash Based Multimedia based on experts at $84,14 \%$ (very valid). The Effectiveness of 2D Flash Interactive Multimedia Based on Usage Tests is measured by the percentage of student learning outcomes classical of 100\% (effective). The Exploration of $2 d$ Flash Game-Based Interactive Multimedia is measured by the results of the percentage of student responses in the trial using 99\% (interesting). These results show that Interactive Flash-Based 2D Multimedia is valid, effective and interesting to use in mathematics subjects Simple Fractions for Class III of UPTD Students at Banyuajuh 4 Elementary School in Kamal.
\end{abstract}

Keywords: Development, Interactive Multimedia, Games, Mathematics.

\begin{abstract}
ABSTRAK
Tujuan pengembangan ini untuk mengembangkan media pembelajaran berbentuk Multimedia Interaktif Berbasis Game 2d Flash pada pembelajaran matematika materi pecahan sederhana yang valid, efektif dan menarik untuk siswa kelas III UPTD SDN Banyuajuh 4 Kamal. Penelitian ini menggunakan model pengembangan Borg and Gall yang dimodifikasi oleh Sugiyono. Berdasarkan hasil penelitian yang dilakukan, diperoleh hasil persentase kevalidan Multimedia Interaktif Berbasis Game 2d Flash berdasarkan para ahli sebesar 84,14\% (sangat valid). Keefektifan Multimedia Interaktif Berbasis Game 2d Flash pada uji coba pemakaian diukur dari tes hasil belajar siswa memperoleh persentase ketuntasan belajar klasikal sebesar 100\% (efektif). Kemenarikan Multimedia Interaktif Berbasis Game 2d Flash diukur dari hasil persentase angket respon siswa pada uji coba pemakaian sebesar $99 \%$ (menarik). Hasil tersebut menunjukan bahwa Multimedia Interaktif Berbasis Game 2d Flash valid, efektif dan menarik digunakan pada mata pelajaran matematika materi Pecahan Sederhana untuk Siswa Kelas III UPTD SDN Banyuajuh 4 Kamal.
\end{abstract}

Kata kunci: Pengembangan, Multimedia Interaktif, Game, Matematika. 


\section{PENDAHULUAN}

Media merupakan suatu alat perantara penyampai materi. Media dapat berfungsi untuk mempertinggi daya serap atau retensi belajar siswa terhadap materi pembelajaran khususnya materi-materi yang sifatnya abstrak. Matematika merupakan ilmu dengan objek kajian yang sifatnya abstrak sehingga penggunaan media dapat membantu mempermudah pemahaman terhadap konsep-konsep matematika. Hal ini menjadi penting karena pengalaman belajar yang tidak konkrit cenderung menimbulkan miskonsepsi.

Penggunaan media pembelajaran memberikan manfaat agar penyampaian pelajaran menjadi lebih menarik (Kemp dan Dayton dalam Arsyad, 2014: 25). Media dapat diasosiasikan sebagai penarik perhatian dan membuat siswa tetap terjaga dan memperhatikan. Kejelasan dan keruntutan pesan, daya tarik image yang berubah-ubah, penggunaan efek khusus yang dapat menimbulkan keingintahuan menyebabkan siswa berfikir-secara keseluruhan menunjukkan bahwa media memiliki aspek motivasi dan meningkatkan minat.

Penggunaan media pembelajaran yang tidak memberi manfaat penyampaian pelajaran menjadi lebih menarik, berdampak pada tidak tercapainya tujuan pembelajaran. Hal ini sejalan dengan pendapat Musfiqon (2011:186) bahwa keberhasilan pembelajaran sangat dipengaruhi kelengkapan sarana atau media yang digunakan. Seperti terjadi di SDN Banyuajuh 4 tepatnya di kelas III. Di sekolah tersebut, guru menggunakan media pembelajaran sederhana berupa kertas warna yang dilipat menjadi beberapa bagian dalam materi pecahan. Namun ternyata siswa kurang tertarik dan kurang berminat dalam mengikuti pembelajaran sehingga berpengaruh terhadap pemahaman siswa - terlihat dari rata-rata hasil belajar siswa di bawah Kriteria Ketuntasan Minimum (KKM).

Pecahan merupakan salah satu materi yang diberikan di sekolah dasar mulai kelas 1 hingga kelas 6 (Permendikbud Nomor 21 Tahun 2016). Materi tersebut merupakan salah satu materi yang sulit diajarkan yang seringkali menimbulkan miskonsepsi. Seperti diungkap oleh Nurhamdiah dan Ahmad Nizar Rangkuti dalam penelitiannya yang berjudul "Profil Miskonsepsi Siswa pada Materi Pecahan Berdasarkan Tingkat Kemampuan Matematika Siswa."

Berdasarkan permasalahan di atas, akan dikembangkan sebuah media pembelajaran yang valid, efektif dan 
menarik untuk materi pecahandifokuskan pada materi pecahan sederhana yakni media pembelajaran "Multimedia Interaktif Berbasis Games 2D Flash Pada Pembelajaran Matematika Materi Pecahan Sederhana”. Dengan adanya media ini diharapkan dapat meningkatkan minat belajar siswa sehingga dapat meningkatkan hasil belajar siswa.

Multimedia interaktif berbasis games adalah media yang didesain dengan sangat menarik dengan memadukan gambar, suara dan teks yang disesuaikan dengan tingkat kesiapan dan kematangan siswa pada rentang usianya. Multimedia interaktif juga dapat dioperasikan oleh siswa sehingga menyenangkan dan memberi kepuasan bagi siswa. Siswa akan memperhatikan penuh terhadap materi sajian materi pecahan yang diberikan, karena pada saat presentasi guru tidak lagi menuliskan materi atau contoh soal di papan tulis sehingga interaksi antara guru dan siswa lebih maksimal.

Multimedia interaktif memiliki beberapa manfaat yaitu: 1) dapat menjelaskan materi pembelajaran atau obyek yang abstrak menjadi konkrit, 2) menarik perhatian peserta didik, sehingga membangkitkan minat, motivasi, aktivitas, dan kreativitas belajarnya, 3) materi pembelajaran lebih lama diingat dan mudah diungkapkan kembali dengan cepat, 4) mempermudah dan mempercepat pendidik menyajikan materi pembelajaran, sehinggga memudahkan peserta didik untuk mengerti dan memahaminya (Munir, 2013:150).

\section{METODE PENELITIAN}

Pendekatan penelitian ini menggunakan Research and Development model Sugiyono yang diadaptasi dari Borg \& Gall (2015: 298). Adapun tahapannya seperti pada Gambar 1 berikut.

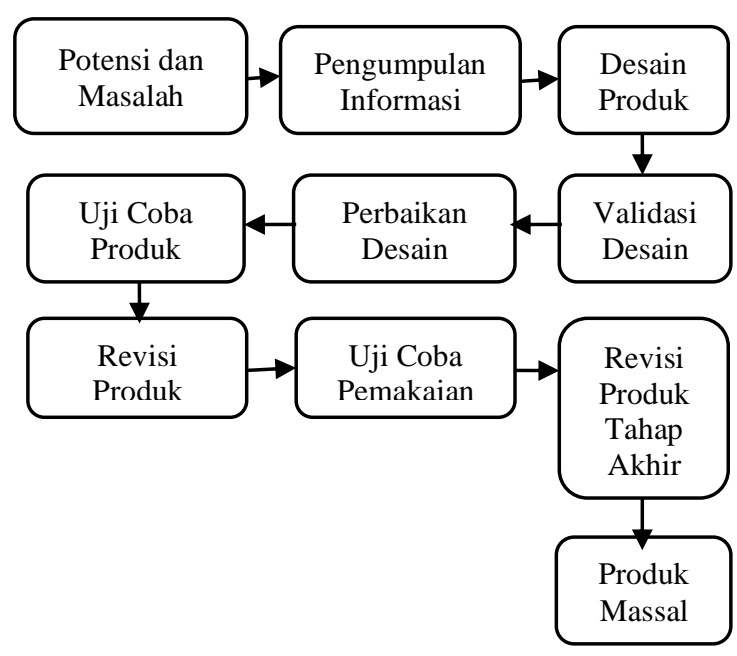

Gambar 1. Tahapan Model Pengembangan Sugiyono Adaptasi dari Borg \& Gall Sumber: Sugiyono (2015: 298)

Prosedur penelitiannya dijelaskan sebagai berikut. Pertama, potensi dan masalah. Pada tahap ini dilakukan identifikasi masalah yang ada di lapangan. 
Kedua, pengumpulan informasi. Pada tahap ini dilakukan analisis kompetensi dasar, merumuskan indikator dan tujuan, studi pustaka. Ketiga, desain produk. Pada tahap ini menyusun RPP, lembar angket, lembar tes, membuat desain awal produk dan memproduksinya. Keempat, validasi desain. Pada tahap ini melakukan validasi ke ahli media, bahasa, ahli materi, dan desain pembelajaran. Kelima, perbaikan desain. Pada tahap ini memperbaiki produk dan perangkat pembelajaran sesuai saran ahli. Keenam, uji coba produk. Pada tahap ini dilakukan uji coba kelompok terbatas pada 6 (orang siswa) kelas III dengan kemampuan yang berbeda. Ketujuh, revisi produk. Pada tahap ini dilakukan perbaikan produk berdasarkan hasil tes, angket dan wawancara pada tahap sebelumnya. Kedelapan, uji coba pemakaian. Pada tahap ini dilakukan uji coba kelompok lebih luas pada 20 siswa kelas III. Kesembilan, revisi produk tahap akhir. Pada tahap ini dilakukan perbaikan produk berdasarkan hasil tes, angket, dan wawancara pada tahap sebelumnya. Sepuluh, produksi masal. Pada tahap ini hasil produk berupa media pembelajaran Multimedia Interaktif berbasis Games $2 D$ Flash dikenalkan dan diaplikasikan pada lembaga sekolah dasar yang lain.
Teknik pengumpulan data dalam penelitian ini adalah: 1) wawancara, digunakan untuk mengetahui dan mengidentifikasi masalah-masalah yang ada dalam pembelajaran dari guru kelas, 2) angket, digunakan untuk mengetahui validasi media pembelajaran dari ahli dan respon siswa setelah menggunakan media pembelajaran Multimedia Interaktif berbasis Games 2D Flash, dan 3) tes hasil belajar, digunakan untuk mengetahui keefektifan pembelajaran menggunakan Multimedia Interaktif berbasis Games $2 D$ Flash.

Subjek uji coba produk dan pemakaian adalah siswa kelas III SDN UPTD SDN Banyuajuh 4 Kamal Bangkalan.

Data dianalisis sesuai bentuk data. Ada dua teknik analisis data yang digunakan dalam penelitian ini yaitu analisis deskriptif kualitatif dan analisis deksriptif kuantitatif.

Analisis deskriptif kualitatif dilakukan untuk menganalisis data berupa tanggapan, kritik, atau saran perbaikan yang terdapat pada angket maupun wawancara di tahap awal pengembangan yaitu tahap potensi dan masalah. Data tersebut dijadikan rujukan untuk perbaikan media yang telah dikembangkan lebih baik. 
Analisis deskriptif kuantitatif digunakan untuk menganalisis hasil angket dan tes hasil belajar untuk mengetahui tingkat kevalidan, keeefektifan, dan kemenarikan media pembelajaran yang dikembangkan. Data hasil validasi dianalisis menggunakan Formula 1. Sedangkan rata-rata gabungan diperoleh dengan menggunakan Formula 2 kemudian dapat ditentukan kriteria kevalidan media seperti pada Tabel 1.

$$
\begin{aligned}
& \text { Vah }=\frac{T s e}{T s h} \times 100 \% \quad \text { (Formula 1) } \\
& \text { Sumber : Akbar (2017: 83) } \\
& \text { Keterangan: } \\
& \text { Vah = Persentase validitas dari ahli } \\
& \text { TSe = Total skor empirik (hasil validasi ahli) } \\
& \text { TSh = Total skor maksimal yang diharapkan }
\end{aligned}
$$

$$
\mathrm{V}=\frac{\mathrm{V}_{\mathrm{ah} 1}+\mathrm{V}_{\mathrm{ah} 2}+\mathrm{V}_{\text {ah3 }}+\mathrm{V}_{\text {ah4 }^{-}}}{4} \quad \text { (Formula 2) }
$$

Sumber : Akbar (2017: 83)

Keterangan:

$\mathrm{V} \quad=$ Validasi gabungan

$\mathrm{V}_{\text {ah1 }} \quad=$ Validasi ahli materi

$\mathrm{V}_{\text {ah2 }}=$ Validasi ahli bahasa

$\mathrm{V}_{\text {ah3 }}=$ Validasi media pembelajaran

$\mathrm{V}_{\mathrm{ah} 4} \quad=$ Validasi desain pembelajaran

Tabel 1. Kriteria Kevalidan

\begin{tabular}{|l|l|c|}
\hline No & \multicolumn{1}{|c|}{ Tingkat Pencapaian } & kategori validitas \\
\hline 1 & $84,00 \% \leq \mathrm{V} \leq 100,00 \%$ & Sangat valid \\
\hline 2 & $68,00 \% \leq \mathrm{V}<84,00 \%$ & Valid \\
\hline 3 & $52,00 \% \leq \mathrm{V}<68,00 \%$ & Cukup valid \\
\hline 4 & $36,00 \% \leq \mathrm{V}<52,00 \%$ & Kurang valid \\
\hline 5 & $20,00 \% \leq \mathrm{V}<36,00 \%$ & Tidak valid \\
\hline
\end{tabular}

Sumber : Akbar (2017: 82)

Data tes hasil belajar dianalisis menggunakan Formula 3. Dari hasil analisis tersebut dapat ditentukan ketuntasan individu seperti pada Tabel 2 kemudian dilanjutkan menentukan ketuntasan klasikal menggunakan Formula 4. Keefektifan media dapat ditentukan menggunakan kriteria keefektifan seperti pada Tabel 3.

Skor $=\frac{B}{N} \times 100$

(Formula 3)

Sumber : Arifin (2016: 229)

Keterangan :

$\mathrm{B}=$ banyaknya soal yang dijawab benar

$\mathrm{N}$ = banyaknya butir soal

$$
\mathrm{P}=\frac{\sum \text { siswa yang tuntas belajar }}{\sum \text { siswa }} \times 100 \%
$$

(Formula 4)

Sumber : Arifin (2016: 229)

\section{Keterangan :}

$\mathrm{P}=$ presentase ketuntasan belajar

Tabel 2. Kriteria Ketuntasan Individu

\begin{tabular}{|c|c|}
\hline Nilai & Keterangan \\
\hline $70 \leq$ skor $\leq 100$ & Tuntas \\
\hline$<70$ & Tidak Tuntas \\
\hline
\end{tabular}

Sumber: Dokumen Sekolah

Tabel 23. Kriteria Keefektifan

\begin{tabular}{|c|c|}
\hline Kriteria Pencapaian & Tingkat keefektifan \\
\hline $85 \% \leq \mathrm{P} \leq 100 \%$ & Efektif \\
\hline $\mathrm{P}<85 \%$ & Tidak Efektif \\
\hline
\end{tabular}

\section{HASIL DAN PEMBAHASAN}

Tampilan media pembelajaran Multimedia Interaktif berbasis Games 2D Flash Materi Pecahan Sederhana seperti pada Gambar 2 berikut. 

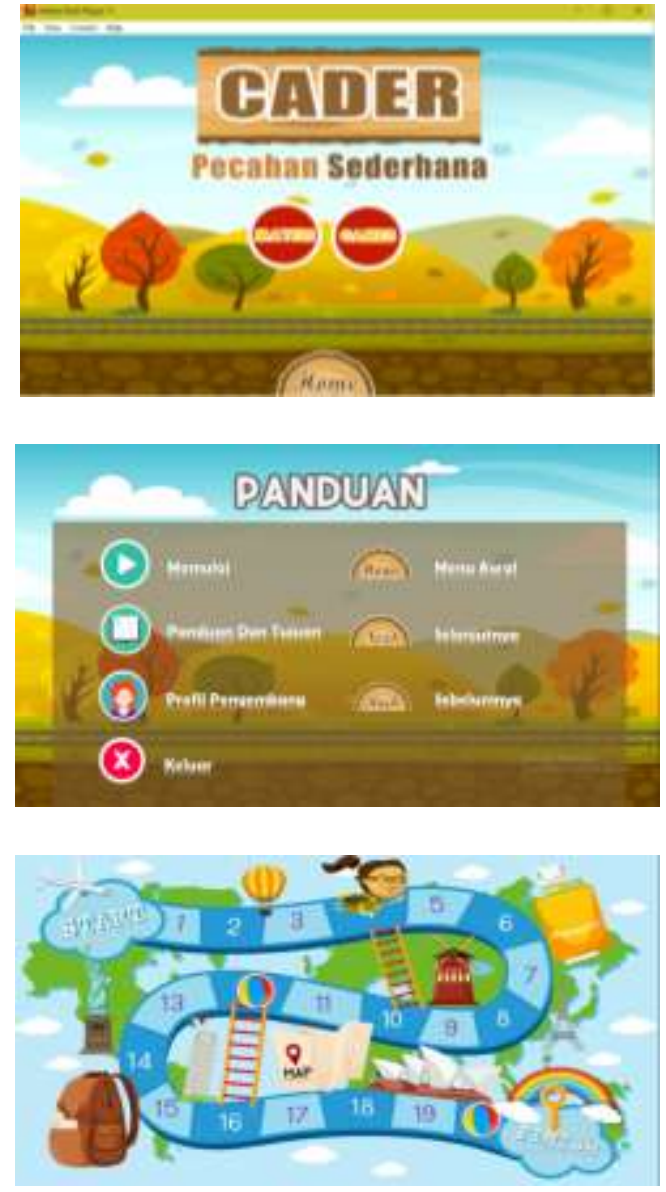

\section{Gambar 2. Tampilan Media Pembelajaran Multimedia Interaktif Berbasis Games 2D Flash Materi Pecahan Sederhana. Sumber: Dokumen Pribadi}

Berikut akan dipaparkan hasil validasi untuk mengetahui kevalidan, tes hasil belajar untuk mengetahui keefektifan dan respon siswa untuk mengetahui kemenarikan terhadap media pembelajaran Multimedia Interaktif berbasis Games 2D Flash Materi Pecahan Sederhana.

\section{Validasi}

Berdasarkan analisis data secara kuantitatif diperoleh hasil sebagai berikut: 1) presentase penilaian ahli materi sebesar $81,66 \%, 2)$ presentase penilaian ahli bahasa sebesar 75,55\%, 3) presentase penilaian ahli media pembelajaran sebesar 90,58\%, dan 4) presentase penilaian ahli desain pembelajaran sebesar 93,33\%. Dari keempat validasi ahli, diperoleh presentase rata-rata sebesar $84.14 \%$. Hasil tersebut jika dikonversikan pada kriteria kevalidan produk Multimedia Interaktif berbasis Games 2D Flash Materi Pecahan Sederhana masuk dalam kriteria sangat valid. Persentase dari setiap validasi ahli disajikan dalam bentuk diagram sebagai berikut.

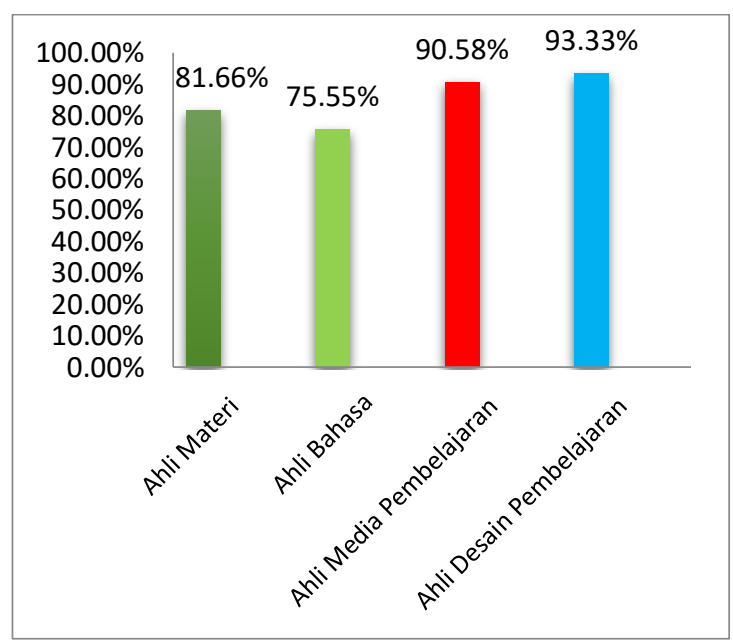

\section{Gambar 2 \\ Hasil Validasi Ahli Sumber: Dokumen Pribadi}

\section{Tes Hasil Belajar}

Pada tahap uji coba produk media, diberikan tes kepada 6 siswa dengan tingkat kemampuan berbeda yang terdiri dari 15 pertanyaan. 
Dari analisis deskriptif kuantitatif, terdapat 2 siswa yang mendapatkan nilai 100, 2 siswa yang mendapatkan nilai 93,33, dan 2 siswa yang mendapatkan nilai 73,33. Dari hasil tersebut menunjukkan seluruh siswa pada uji coba produk dinyatakan tuntas, karena nilai seluruh siswa sudah memenuhi nilai KKM yakni diatas 70. Sedangkan nilai rata-rata siswa diperoleh $\quad 88,88$ dan memperoleh ketuntasan belajar klasikal sebesar 100\%. Berdasarkan kriteria keefektifan bahwa media dikatakan efektif apabila ketuntasan klasikal minimal $85 \%$. Sehingga dapat disimpulkan bahwa media pembelajaran Multimedia Interaktif berbasis Games 2D Flash Materi Pecahan Sederhana pada tahap uji coba produk dinyatakan efektif.

Pada tahap uji coba pemakaian, diberikan tes kepada 20 siswa kelas III yang terdiri dari 15 pertanyaan.

Dari analisis deskriptif kuantitatif, terdapat 11 (sebelas) siswa yang mendapatkan nilai 100, 4 (empat) siswa yang mendapatkan nilai 93, 1 (satu) siswa yang mendapatkan nilai 87, dan 3 (tiga) siswa yang mendapatkan nilai 73. Dari hasil tersebut menunjukkan seluruh siswa pada uji coba pemakaian dinyatakan tuntas, karena nilai seluruh siswa sudah memenuhi nilai KKM yakni diatas 70 .
Sedangkan nilai rata-rata siswa diperoleh 93,67 dan memperoleh ketuntasan belajar klasikal sebesar 100\%. Berdasarkan kriteria keefektifan bahwa media dikatakan efektif apabila ketuntasan klasikal minimal $85 \%$. Sehingga dapat disimpulkan bahwa media pembelajaran Multimedia Interaktif berbasis Games 2D Flash Materi Pecahan Sederhana pada tahap uji coba pemakaian dinyatakan efektif.

\section{Respon Siswa}

Angket respon siswa dilakukan untuk mengetahui tingkat kemenarikan terhadap Multimedia Interaktif Berbasis Games $2 D$ Flash.

Pada tahap uji coba produk, angket diberikan kepada 6 siswa dengan tingkat kemampuan berbeda dengan memuat 10 butir pertanyaan. Pada tahap ini diperoleh total skor 54 dengan skor maksimal 60. Dari skor tersebut diperoleh persentase 98,33\%. Konversi terhadap kriteria kemenarikan media disimpulkan bahwa Multimedia Interaktif Berbasis Games 2D Flash yang digunakan dalam pembelajaran mendapatkan kriteria sangat menarik.

Pada tahap uji coba pemakaian, angket diberikan kepada 20 siswa. Pada tahap ini diperoleh total skor 198 dengan 
skor maksimal 200. Dari skor tersebut diperoleh persentase $99 \%$. Konversi terhadap kriteria kemenarikan media disimpulkan bahwa Multimedia Interaktif Berbasis Games 2D Flash materi pecahan sederhana yang digunakan dalam pembelajaran mendapatkan kriteria sangat menarik.

Dari tahap uji coba produk dapat disimpulkan bahwa media pembelajaran Multimedia Interaktif Berbasis Games 2D Flash materi pecahan sederhana efektif dan sangat menarik. Presentase hasilnya ada pada Gambar 3. Sedangkan pada tahap uji coba pemakaian dapat disimpulkan bahwa media pembelajaran Multimedia Interaktif Berbasis Games 2D Flash materi pecahan sederhana efektif dan sangat menarik. Presentase hasilnya ada pada Gambar 4.

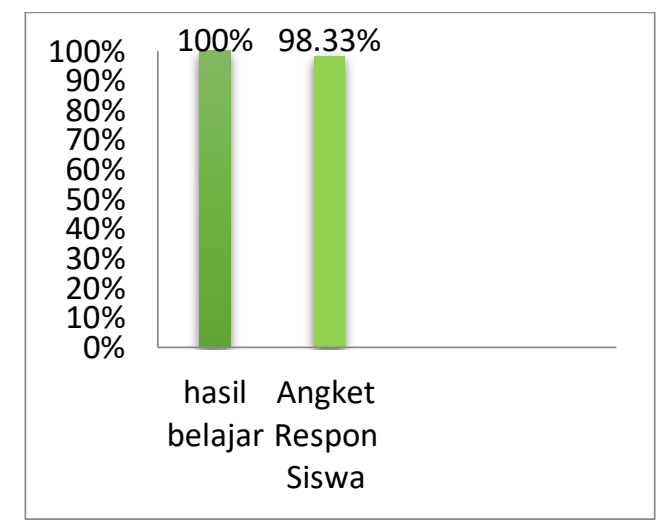

Gambar 3

Persentase Hasil Uji Coba Produk Sumber: Dokumen Pribadi

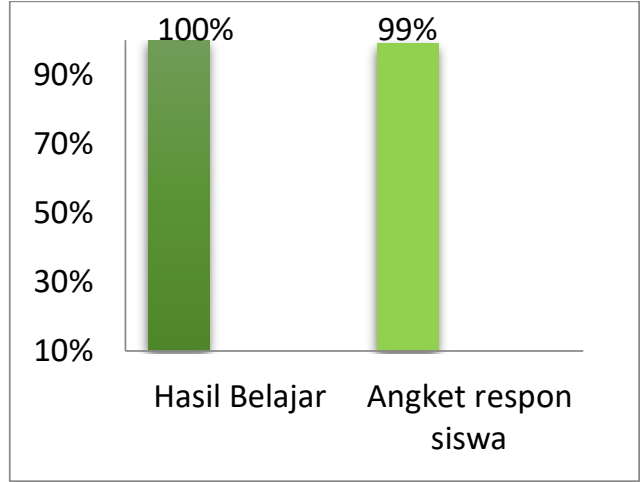

\section{Gambar 4}

Persentase Hasil Uji Coba Pemakaian Sumber: Dokumen Pribadi

\section{SIMPULAN DAN SARAN}

\section{Simpulan}

Produk pengembangan ini adalah media pembelajaran Multimedia Interaktif Berbasis Games 2D Flash pada Pembelajaran Matematika Materi Pecahan Sederhana. Model pengembangan yang digunakan adalah model pengembangan Sugiyono adaptasi dari Borg \& Gall dengan tahapan: 1) Potensi dan masalah, 2) pengumpulan informasi, 3) desain produk, 4) validasi desain, 5) perbaikan desain, 6) uji coba produk, 7) revisi produk, 8) uji coba pemakaian, 9) revisi produk tahap akhir, dan 10) produksi massal. Seluruh tahapan pengembangan ini telah dilakukan dan menghasilkan suatu produk media pembelajaran yang sangat valid, efektif dan sangat menarik.

\section{Saran}

Saran pemanfaatan produk dari pengembangan Multimedia Interaktif 
Berbasis Game 2D Flash dengan materi pecahan sederhana untuk guru yakni agar guru dan siswa menggunakan media pembelajaran ini sebagai alternatif untuk memudahkan siswa memahami materi pecahan dan membuat pembelajaran semakin menarik dan menyenangkan sehingga memotivasi siswa untuk semangat belajar. Dengan pembelajaran yang kondusif tersebut diharapkan siswa dapat meningkatkan hasil belajarnya. Untuk pengembang yang lain diharapkan dapat media ini sebagai acuan untuk mengembangkan media yang sama atau media lainnya.

\section{DAFTAR PUSTAKA}

Akbar, Sa'dun. 2013. Instrumen Perangkat Pembelajaran. Bandung: PT. Remaja.

Arifin, Zainal. 2016. Evaluasi Pembelajaran. Bandung : PT. Remaja Rosdakarya.

Arsyad, Azhar. 2016. Media Pembelajaran. Jakarta: PT. Raja Grafindo Persada.

Munir. 2013. Multimedia konsep \& Aplikasinya dalam Pendidikan. Bandung: CV Alfabeta.

Musfiqon. 2012. Pengembangan Media dan Sumber Pembelajaran. Jakarta: Prestasi Pustaka.

Sugiyono. 2015. Metode Penelitian Kuantitatif, Kualitatif dan R\&D Bandung:Alfabeta.

Permendikbud Republik Indonesia Nomor 21 tahun 2016 tentang Standar Isi Pendidikan Dasar dan Menengah 